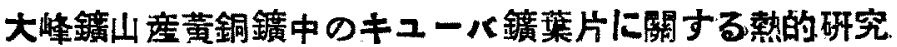

\section{(岩手県大峰鉱山産銅鉱石D研究 III)}

Thermal Studies on the Cubanice Lamellae in

Chalcopyrite from the Omine Mine.

(Studies of the Copper Ores from the Omine Mine, Iwate Prefecture, III)

\section{望木 浅 彥 Asahiko Sugaki)}

\begin{abstract}
Under the microscope, cubanite is found in lamellae and massive crystals in chalcopyrite from the Omine mine, I wate Prefecture. The lamellae run parallel to [111] of chalcopyrite, as shown in Figs. 1 and 2, and are thought to be an unmixing product from a sulid solution, while the massive crystals are believed to be a primary product from the ore solution. When both cubanite in chalcopyrite are heated in sealed tubes, the following process is observed.
\end{abstract}

1) No change is observed at temperatures from $300^{\circ} \mathrm{C}$ to $340^{\circ} \mathrm{C}$.

2) At $350^{\circ} \mathrm{C}$ for 90 hours, at $400^{\circ} \mathrm{C}$ for 50 hours or at $450^{\circ} \mathrm{C}$ for irom 5 to 10 hours, lamellar cubanite changes by mutual reactions with surrounding chalcopyrite into saw-toothed bodies, as shown in Fig. $3 \mathrm{~A}$.

3) At $400^{\circ} \mathrm{C}$ for 100 hours or at $500^{\circ} \mathrm{C}$ for from 5 to 15 hours, the cubanite lamellae suffer conspicuous diffusion from chalcopyrite, and thus converting into microgaphic or lattice-shaped intergrowth of two minerals, as shown in Figs. $3 \mathrm{~B}, 5$ and 6.

4) A margin of massive cubanite changes by heating at $400^{\circ} \mathrm{C}$ for from 50 to 100 hours into irregular form the same as 2), as shown in Fig. 7.

5) At temperatures from $450^{\circ} \mathrm{C}$ to $500^{\circ} \mathrm{C}$, pyrite appears in cubanite and chalcopyrite as granular, worm-like and dendritic crystals, as shown in Fig. 8

From the results of experiment, it is concluded that the solid solution of lamellar cubanite and surrounding chalcopyrite may be perfectly formed by heating at temperature of about $350^{\circ} \mathrm{C}$ in such long times as the geological process.

前

言

岩手県大峯鉣山産銅鉱石の共生関係については 既に本誌り一㗇じた通

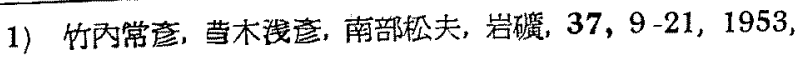


りー゙する。それ記誡された様に，黃銅鉱中汇は多量のキ_ーバ鉱がみら

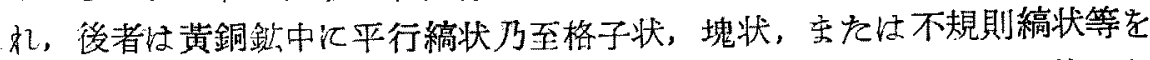

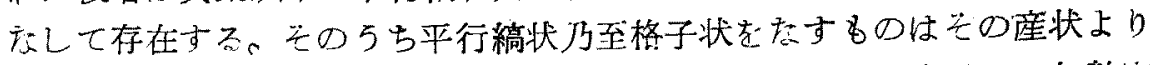
離溶性産物之認められるもので，篗者的特にこの共生体に注目して加熱実 駼を行なつを。

向乙の外本黃銅鈗中には1黃銅鉱一磁硫鉄鈗格子状共生, 2)

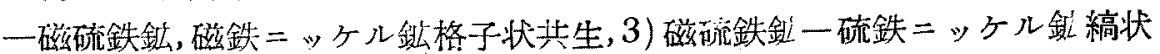

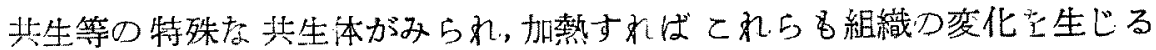
がこ」では上記黄銅鋩———バ釯共生体の加熱変化のみに着目し，他の 変化汇ついては後日沈らつる。

\section{實 驗 の目 的}

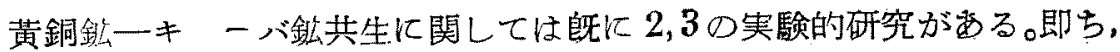
1927 年 G. M. Schwartz は黄銅鈗中のキ二ーバ釯格子にこいて加熱実

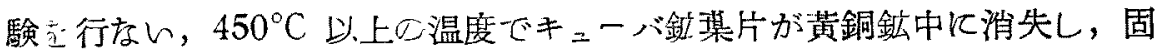
溶体在形成する現象家認めて居り，1937 年 Merwin-Lombard ${ }^{1)}$ \&李 た $400^{\circ} \mathrm{C}$ 以上ひ温度で両鉱物が完全な固溶体形成すると述べている。 一方 $\mathrm{H}$. Borchert ${ }^{2)}$ はキニーバ鉱を $235^{\circ} \mathrm{C} \sim 300^{\circ} \mathrm{C}$ 以上䎲熱してて れが黄銅鈗と磁硫銅鈗 (chalcopyrrhotine) と代分裂する現象老認め。 キ ニ一バ鈗はをの温度以下て安定ですると述べ，前両者の值よりかなり低い 温度苦出している。

そこで筆者は上記 3 者の実駼結果を吟味する目的で，当釷山産 黄銅鎕 一キュ一バ鈸縞状共生体の加熱実験を試みをので西る。

\section{貫 驗 の方 法}

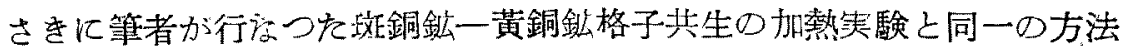

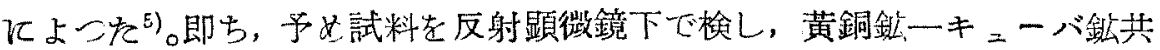
生体の状態を充分確加めを後，SBB 硝子管中に試料の一片を密封し，電 気爐中一゙加熱, 加熱後は直ちに水冷或は室冷し, 再び研磨して顕微鏡下で 共生組織の変化を観察した。

2) G. M. Schwartz, : Econ. Geol., 22, 44-61, 1927.

3) H. E. Merwin, R. H. Lombard: Econ. Geol., 32, 203-284, 1937.

4) H. Borchert: Chemine d. Erde, 9, 145-172, 1934.

5) A. Sugaki : Sci. Rept. Tohoku Univ., Ser. 3, 4,11-17, 1951 
奏験中温度を一定に保つために電位差計式自動温度調節計を使用した。 てれを用いるととによつて長時間加熱の場合でも略々 $\pm 2^{\circ} \sim 5^{\circ} \mathrm{C}$ の範囲 で所定の温度に保つととが出来た。

\section{加熱前のキューパ鑛葉片}

反射顕微鏡下で当キーバ鉱葉片は Fig. 1 及び Fig. 2 の如く幅 0.03〜 $1.3 \mathrm{~mm}$, 普通 $0.1 \sim 0.3 \mathrm{~mm}$ 内外, 長さ $1.5 \sim 9.0 \mathrm{~mm}$ 普通 $2.0 \sim 4.0$

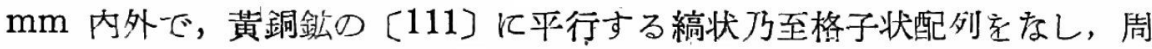

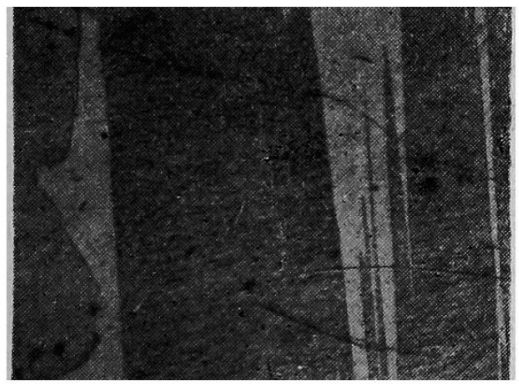

Fig 1. Cubanite (dark gray in chalcopyrite (light gray) $\times 65$.

囲の黃銅鉱とは直線的境界觉以つて接 するが，その尖端学震々分派して比較 的等飞尖隇する。その量的割合は一般 に黃銅鉱に比し少量であるが，部分に よつてはかなり多量存在し, 逆汇キュ 一バ鉱中记黃銅鉱の平行縞を含有する 場合も稀で疗ん。特汇キ 一バ鉣葉片 の大きいのは研磨面中肉眼でも容易 代認められる。今㷊片の反射顕微鏡下 の榄質を記世ば次の㥞である。

1) 反射多色性

縞つ方向 //二ヨルの振動方向; 淡紅灰色〜タリーム黄色

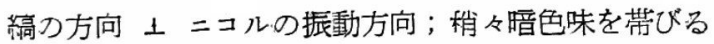

2）異 方性（直交ニコル下）顯著, 但し磁硫鉄鉱より弱、 䋧の方向 $/ /$ ニコルの振動方向; 淡灰青色〜淡灰綠色 䋨の方向 $/ / 45^{\circ}$ の方向; 淡青灰色〜淡灰黄色 綃の方向 $/ /-45^{\circ}$ の方向; 淡紅褐色

3) 硬 度 Low 黄銅鉱と略々一致，磁硫鉄鉣上り低い

4)腐蝕試臨

$\mathrm{HNO}_{3}\left(\begin{array}{ll}1 & 1\end{array}\right) ;$ 蒸気にて裉色に錆る。

$\mathrm{KOH}$ (Sat.)；徐々江褐食。

$\mathrm{KCN}(20 \%)$ ；長時間放置すれば褐訟。

$\mathrm{HCl}(1: 1) ， \mathrm{HgCl}_{2}$ (Sat.), $\mathrm{FeCl}_{3}(20 \%)$ ；腋化せず。

キ二一バ鉱は京を震々黄銅鉱中大きさ $0.3 \sim 3.0 \mathrm{~mm}$, 普通 $0.5 \sim 2.0$ " $\mathrm{mm}$ 程度の塊状をなして, かなり多量現われる。もつともこの一部には 上記葉片が研磨面の方向汇よこて塊状となつたものもするが，他のものは 
周囲の黃銅釯によ二て寧ろ交代された様な不規則な産状を呈し，なたその 大きさや，黄銅鉱に刘する量的関係から直接鉱液より生成されをと解しを

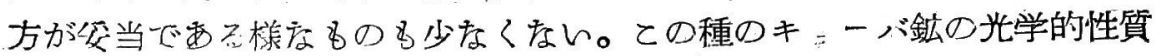
葉片状の子のと全く同标である。

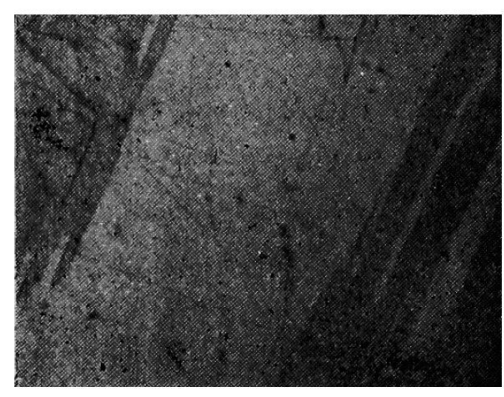

Fig. 2. Lamella1 cubanite (dark gray) in chalcopyrite (light gray). $\times 65$

橫銅鎕の交代作用を受けを之思わ れるるのは, 鋸歯状に烈しく出入する

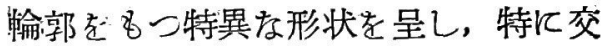
代の程度の進んだものは不規則縞状と なる。

本実験飞供しを試料は上記の5ち 葉片状キュ一バ鉱を含有する黄銅鉱を 顕微鏡的に選別して使用しそが，一部 塊状キ:ニーバ鉱家含さ黄銅鉣をる加熱 し，その変化を顴察した。
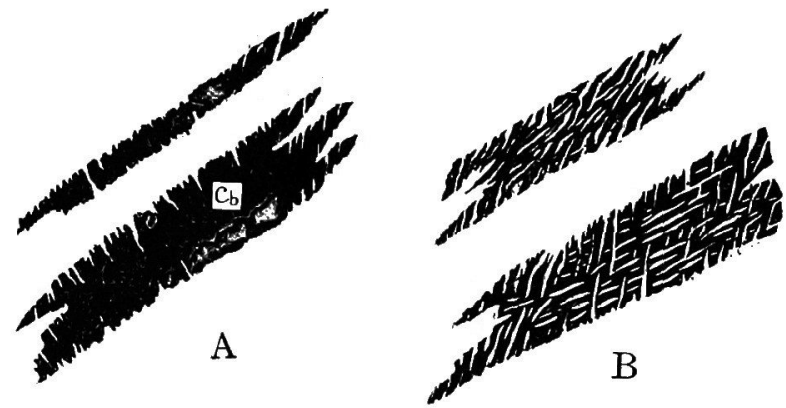

Fig. 3. Change of cubanite (Cb, black) lamellae in chalcopyrite (white) by heating. A, $450^{\circ} \mathrm{C}, 5$ hours, B, $500^{\circ} \mathrm{C}, 5$ hours. $\times 65$.

\section{キューハ鑛葉片の加熱變化}

$300^{\circ} \mathrm{C} \sim 350^{\circ} \mathrm{C}$ 以下の加熱で仕 殆ん ゙゙無変化で, Borchert ${ }^{1)}$ の云う様 なキ_一バ鉱の分裂炕よる黄銅鉣一磁硫銅鉙共生体の生成は認められな

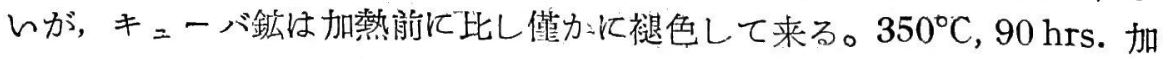
熱の場合にも殆んど変化はみられないが，稀沉キニ一バ鉱某片の尖端部の

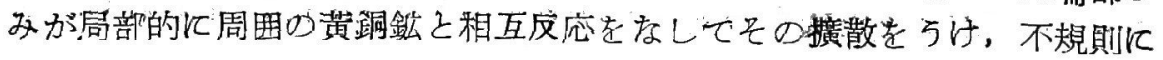

1) H. Bórchert: Op cit: 


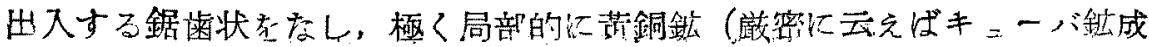

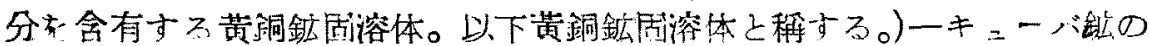
微文象状組織在形成子万場合が要る。

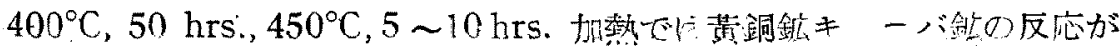

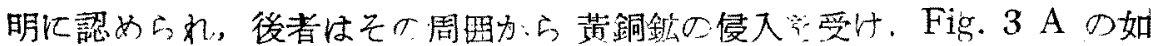

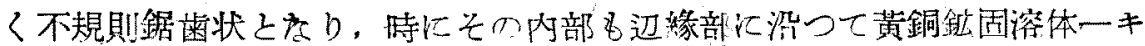

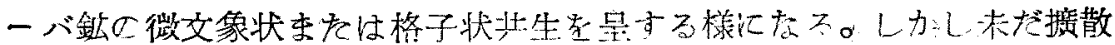

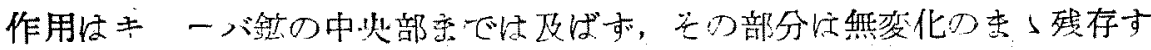

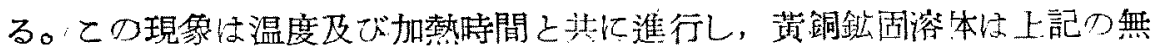

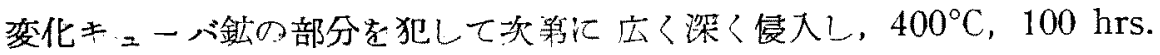

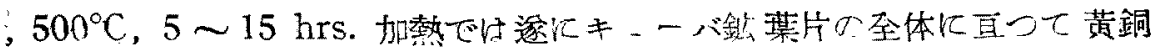

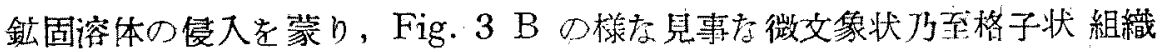
を形成する。特汇薄い葉片は大部分吸收されて, Fig. 4 の栏江僅か，断片 状汇残存する程度とな不。この格子状組織汇ついては炏頁で說明する。

しかしながら上記の加熱条件内で注

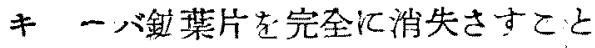
が出来吉，乙れ在消失させるためには 更汇高温或は長時間の加熱が必要であ る。 $550^{\circ} \mathrm{C} \sim 600^{\circ} \mathrm{C}$ 以上の温度飞な れば，本実験汇使用した SBB 管は卧 化して破損するので，石英管老用い底 ければをらない。故炕今得は石英の密 封管中で高温の加熱実験索行度い，完 全固溶化の条件它決定する予定で る。

なお本奏験中注意しなければならな い点は、キニーバ鉱が加熱汇上り裉色

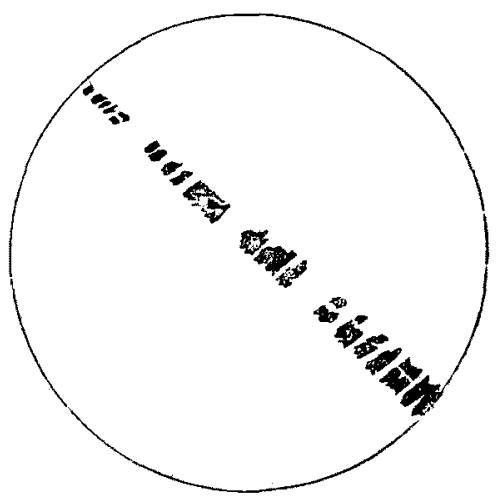

Fig. 4. Change of thin lamellar cubanite (black) in chalcopyrite (white) by heating at $500^{\circ} \mathrm{C}$ for 5 hours $\times 110$.

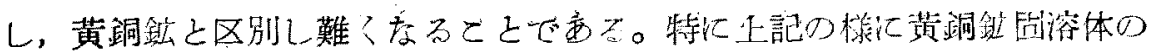

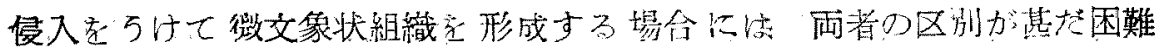

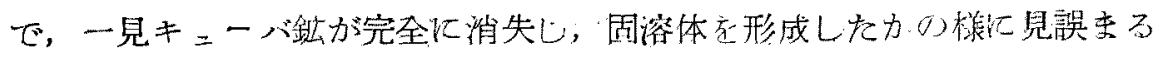

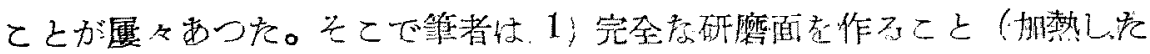

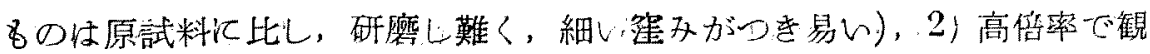

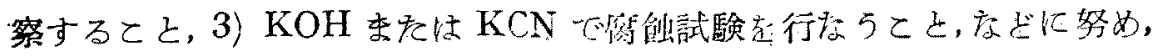

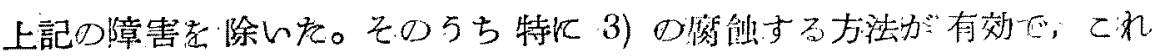
に上つて残存キ三一バ航の状態をよく観察するととが出来た。 


\section{キューハ鑛一簧銅鑛格子狀組織}

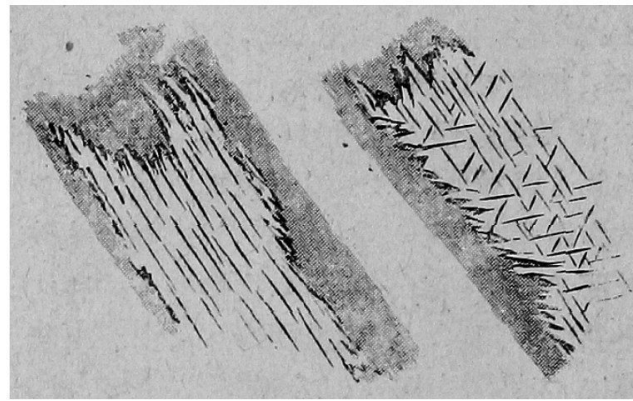

Fig. 5. Lattice-shafed patterns of chalcopyrite (black) invaded into cubanite by heating at $500^{\circ} \mathrm{C}$ for 5 hours. Dark grourd, chalcopyrite.
上記の如くキニーバ鉣中化侵 入しを賃銅鉱（詳しく云えばキ —一バ鉱成分を固溶しを黃銅 鉱)は普通一定の方向を有して居 b，之の酒矵活

1) キ =ーバ鉱葉片の仲長方 向之略々平行する百の (Fig.5左)

2) $60^{\circ}$ 內外の角度で交叉す る正三角形状の \&の（Fig. 5 右 及ひ” Fig. 6)

3）直交またはそれに近い角 度で交叉するもの (Fig. 3 B) 等で恐らくキニーバ鉣の[001]江平 行した方向汃之思われる。侵入、黃銅 鉣の葉片はFigs.5,6でみられる椂に， 交羿部化於て少をくともとの一方

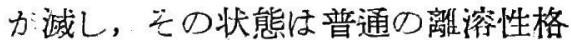
于組織と極めてよく類似する。噍こ の瑒合，黃銅鉱㸃片はキューバ鉱の 緣辺部で周囲の黃洞鈗と連絡】ててい る。この様店現象汇よこて格子状組 織力形成されるととは鎹石組織の研 究上留意さるべきである5。
Fig. 6. Lattice intergrowth fo cubanite ( $\mathrm{Cu}$, dark gray) and invaded chalcopyrite $(\mathrm{Ci}$, lightgray) formed urder the same conditions as Fig. 5. Ch, chalcopyrite. $\times 300$

\section{塊狀キューハ鑛の加熱孌化}

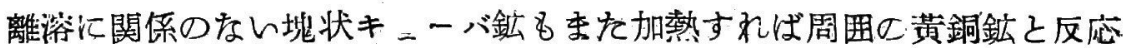
して，㹃片状のものと同様形状変化する。すなわら，

1) $300^{\circ} \mathrm{C} \sim 350^{\circ} \mathrm{C}:$ 殆んど変化しない。

2、 $400^{\circ} \mathrm{C}, 50 \sim 100 \mathrm{hrs}$ ：周緣部より黃銅鉱の侵入を蒙つてキューバ 鉣塊つ境界心 Fig. 7 の様に，不規則に出入する。

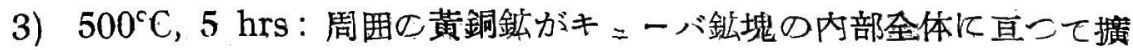
散し，その結果として後者は侵入した带銅鉱固溶体こ残存キ_ーバ鉱との 
微文象状乃至格子状組織となる。

の様である。しかし，ての固溶化現象は某 片状の承のに比しゃ劣る。てれと同㥞な 現象は斑銅鈗とクラプロート鉱 (klaprothite) まえ沬ウイチヘン鉳 (wittichenite) との間记於てを観察される11。

\section{黄鐵鐄樣鐄物の現出}

上記寄験中 $450^{\circ} \sim 500^{\circ} \mathrm{C}$ 江於て時に黄 鉄鉣に類似した鉝物で現出がみられる。こ の釷物云黃銅鉣及びキ_ーバ鉱の両者中に

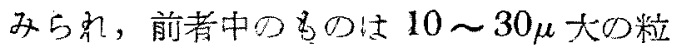

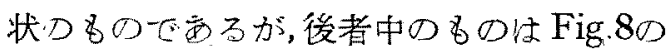

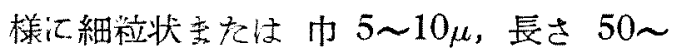

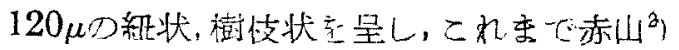

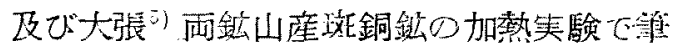

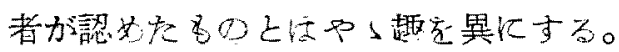

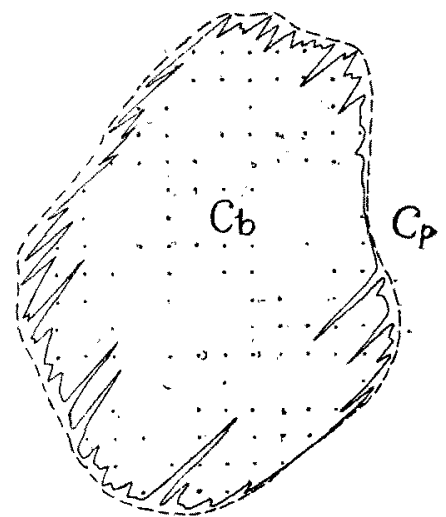

Fig. 7. Change of massive cubanite $(\mathrm{Cb})$ in chalcopyrite (Cp) by heating at $400^{\circ} \mathrm{C}$ for 100, hours. Dotted line, boundary between cuhanite and chalcopyrite before heating. $\times 55$

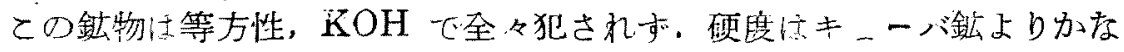

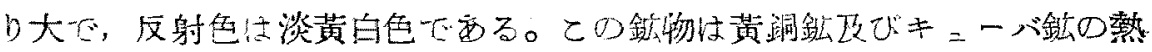

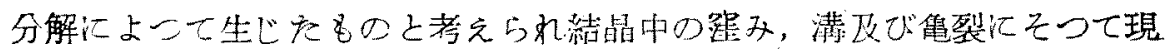
われる傾问がある゙。

\section{結}

\section{言}

上記の奏験結果要要䄪す礼ば

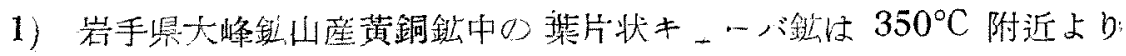

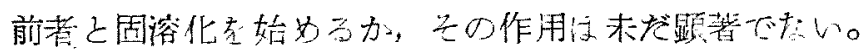

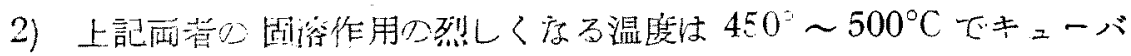

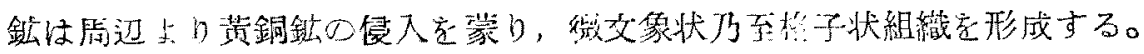

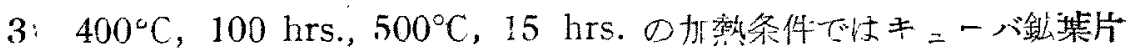
是完至江消失さすとと住出来症的。

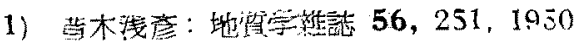

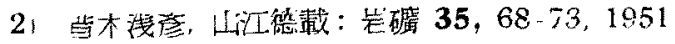

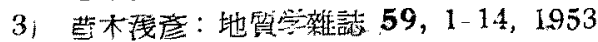

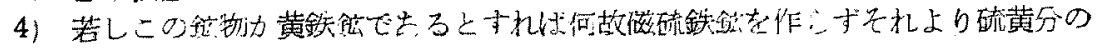

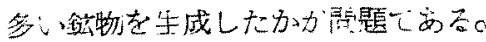




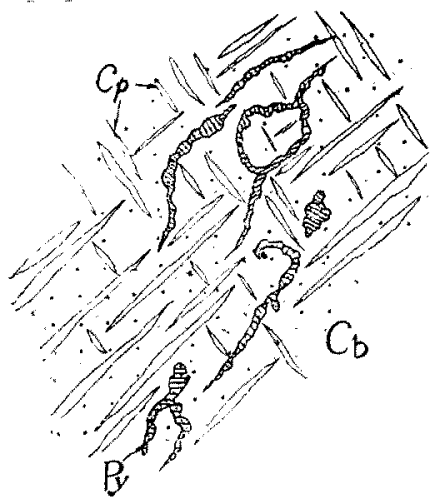

Eig. 8. Pyrite (Py) produced by dissociation of cubanite (Cb) at $500^{\circ} \mathrm{C}$ for 5 hours. $\mathrm{Cp}$, invaded chalcopyrite. $\times 250$.
4) 塊状 上り周囲の黃銅鉱の㻏入告許してその外形 を変化し，500 ${ }^{\circ} \mathrm{C}$ 以上の加熱で，侵入Lを黃 銅鉱と残存キューバ鉱上よりなる微文象状 乃至格子状組織者形成する。

5) $450^{\circ} \mathrm{C} \sim 500^{\circ} \mathrm{C}$ 附近で黄銅釙及びキ 二一隹鉱中以黃鉄鉱棁鉱物考現出する。 となる。しかしながら本実験法決して完了し をわけではなく、今後更汇

a) キューバ釷葉片の完全消失

b) a)に上こて生成された固溶体の離溶現象 と兰の組織

c）塊状キ二－バ鉱一黃銅鉙 2 次的固溶体 ${ }^{1)}$ の離溶現像

d）黃銅鉱及びキュー八゙鉱の熱分解

等の点走解決しなければなら度い唯上記の結果から次のとと文は云える 梯炕思 5。

1) キニーバ鉱の分解化上る磁硫銅鉱の生成壮認好的ない (Borchert の英験之の租異)

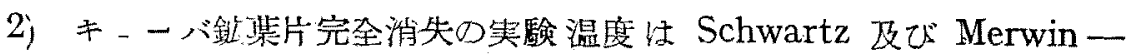
Rombard の关れ上りか格り高值が予想される。

3）もし極文て長期間一地質学的時間一の加熱が可能であるならば，2) ○值屯固溶化閉始つ温度える $350^{\circ} \mathrm{C}$ 附近几落着く可能性がある。

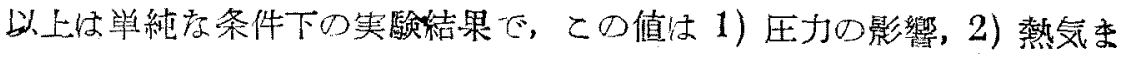

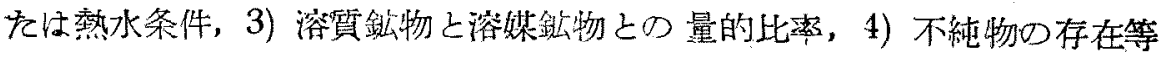
によつてかなり変化すると考えられる。故に，乙の值索淔らに地質学的温

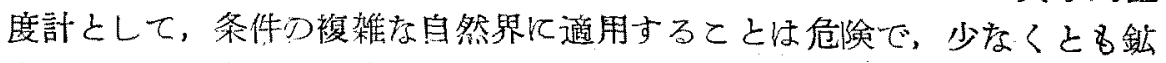

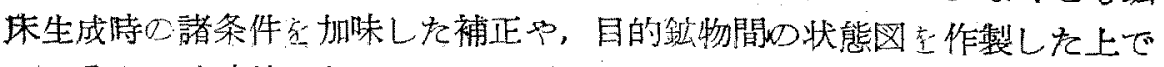

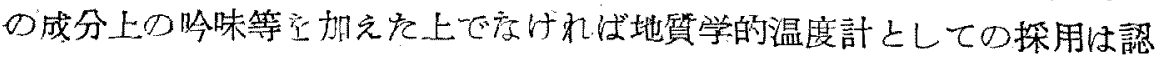

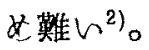

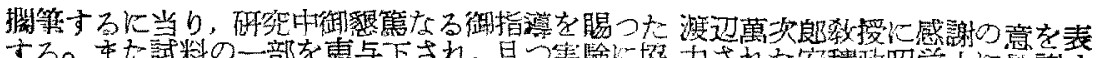

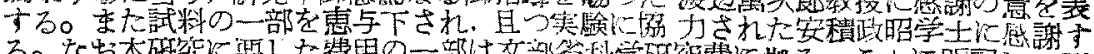

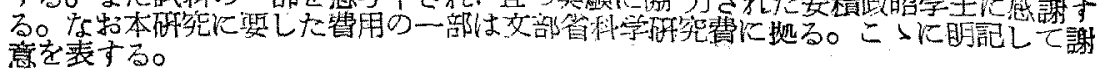

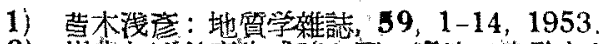

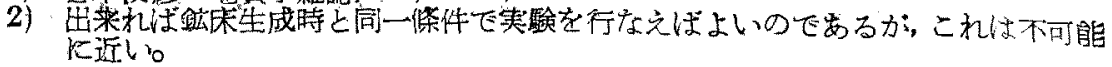

